\title{
Citrus sinensis Extract as a Green Inhibitor for the Corrosion of Carbon Steel in Sulphuric Acid Solution
}

\author{
Amira E.Ali ${ }^{1}$, Gamila E. Badr ${ }^{1}$, Abd El-Aziz S. Fouda ${ }^{1, *(D)}$ \\ 1 Chemistry Department, Faculty of Science, Mansoura University, Mansoura-35516, Egypt; asfouda@ hotmail.com \\ (A.A.F.); badrgamila@hotmail.com (G.E.B.); ameraali373@yahoo.com (A.E.A.); \\ * Correspondence: asfouda@ hotmail.com;
}

Scopus Author ID 56231506400

Received: 26.01.2021; Revised: 22.02.2021; Accepted:25.02.2021; Published: 2.03.2021

\begin{abstract}
Citrus sinensis extract is considered a good inhibitor to protect the carbon steel in half of molar of sulfuric acid from corrosion, as it was found from the results of chemical methods such as the weight loss (ML) method and also from the results of electrochemical methods such as potentiodynamic polarization (PP), electrochemical impedance spectroscopy (EIS) and electrochemical frequency modulation (EFM). The polarization curves indicated that this extract acts as a mixed kind inhibitor. The adsorption of this extract on the carbon steel surface is of mixed type physisorption and chemisorption, but chemisorption is the most effective one and followed Temkin adsorption isotherm. Several tests have proved a layer that protects carbon steel from corrosion.
\end{abstract}

Keywords: Citrus sinensis; corrosion inhibition; $\mathrm{HCl}$; carbon steel; adsorption.

(C) 2021 by the authors. This article is an open-access article distributed under the terms and conditions of the Creative Commons Attribution (CC BY) license (https://creativecommons.org/licenses/by/4.0/).

\section{Introduction}

Corrosion is a natural process in which an unstable metal is transformed into a chemically stable form, such as oxide and hydroxide forms, by reacting the mineral chemically or the electrochemical with the surrounding environment [1]. Corrosion is an undesirable phenomenon as it destroys the beneficial properties of the mineral [2]. Metals do not corrode similarly; for example, aluminum metal does not corrode easily like other metals because there is an oxide layer on its surface because it is reactive [3]. Some factors affect corrosion: temperature, impurities such as salts, exposure of minerals to gases such as carbon dioxide, and exposure of minerals to acids in the atmosphere. Most corrosion inhibitors are synthetic chemicals, expensive, and hazardous to the environment. So, the need to use sources of environmentally safe corrosion inhibitors is being required $[4,5]$. Green corrosion inhibitors are compounds of plant origin, hence are cheap, biodegradable, and do not contain heavy metals or other $\mathrm{n}$ toxic substances. The action of plant extracts on the metal surfaces is the adsorption of the phytochemicals present in the plant onto the metal surface $[6,7]$, thus preventing the corrosion process from taking place [8-17].

\section{Materials and Methods}

\subsection{CS samples.}

The carbon steel composition is shown in Table 1. 
Table 1. Chemical composition (weight \%) of carbon steel

\begin{tabular}{l|c|c|c|c|c} 
Material & $\mathbf{C}$ & $\mathbf{M n}$ & $\mathbf{P}$ & $\mathbf{S}$ & $\mathbf{F e}$ \\
\hline (wt.\%) & 0.610 & 0.754 & 0.013 & 0.254 & Balance
\end{tabular}

\subsection{Plant extract.}

Citrus sinensis is used as plant extract in order to protect carbon steel from corrosion.

2.2.1. Chemical composition.

List of some phytochemical constituents isolated from Citrus sinensis extract as reported in Table 2:

Table 2. Chemical constituents of Citrus sinensis extract.

Cyanidin 3-(6"-malonylglucoside)

\subsection{Solutions.}

Ethyl alcohol, DMF, $\mathrm{H}_{2} \mathrm{SO}_{4}$, all of the Analar grades, distilled water.

\subsection{ML test}

The carbon steel metal is divided into pieces of equal length and width and is sanded using sandpaper in degrees of 150, 400,600,1000, and 1200, then weighed, and then placed in a half-molar solution of sulfuric acid with and without various doses of the plant extract and then measuring the weight after immersion every half hour for a period of three hours after drying it. Then calculate the percentage of inhibition (\%IE) and also surface coverage $(\theta)$ by using this equation: 


$$
\% \mathrm{IE}=\theta \times 100=\left[1-\frac{\text { Winh }}{\text { Wfree }}\right] \times 100
$$

Where $\mathrm{W}_{\mathrm{nh}}$ is the weight of carbon steel pieces in the existence of extract $\mathrm{W}_{\text {free }}$ is the weight of carbon steel pieces in the absence of extract

\subsection{Electrochemical methods.}

This kind of dissolution is caused between the medium and the metal or the composition, accompanied by the transfer of electrons between two sites on the surface, one of which has a high electron density and another with a low density, or between two points, one of which is of low voltage and the other with a high voltage in the presence of an electrolyte. These methods are the Tafel extrapolation method, linear polarization method, and impedance method. The advantages of these methods are that they take a short time with the highest accuracy [18-21].

The protection efficiency (\%IE ) and surface coverage $(\theta)$ obtained from potentiodynamic polarization (PP) are given by :

$$
\% \mathrm{IE}=\theta \times 100=\left[1-\frac{i \operatorname{corr}(\text { inh })}{i \operatorname{corr}(\text { free })}\right] \times 100
$$

Where $i_{\text {corr(inh) }}$ is the corrosion current density in the existence of the extract. $\mathrm{i}_{\text {corr(free) }}$ is the corrosion current density in the absence the extract

\subsection{Surface characterization.}

2.6.1. Atomic forced microscopy (AFM) analysis.

This method is used to determine the morphology of the carbon steel surface in existence and lack of the extract. Carbon steel parts are dipped in solutions that are prepared in the same way as weight loss in the absence and the highest dose of the extract for a day at room temperature. After this period has passed, these pieces are taken after washing with distilled water and then drying. The surface of carbon steel was analyzed by AFM in contact mode using silicon nitride probe model MLCT manufactured by Bruker, using prosan 1.8 software to control the scan parameters and IP2.1 software.

\subsubsection{Fourier Transform Infrared Spectroscopy (FTIR) analysis.}

This technique is performed on the extract only and on the layer that protects the carbon steel surface immersed in a half-molar solution of sulfuric acid and the highest dose of the extract for a day.

\section{Results and Discussion}

\subsection{ML method.}

The carbon steel strip is divided into 7 equal parts. They are sanded, then weighed. The first piece is placed in a half-molar solution of sulfuric acid, and the rest of the pieces are placed in different doses of the extract from a dose of 50 to $300 \mathrm{ppm}$ for a period of three hours, noting that every half hour, these pieces are taken out after washing with distilled water, then dried and weighed [22-25]. By raising doses, the kcoo decreased $(\Theta)$, \% IE increased as in Table 3. From Fig. 1 the curves in the presence of various doses of extract lie below that in its absence. 
The ML-time curves are approximately lines indicating the absence of oxide film on the carbon steel surface.

Table 3. The rate of corrosion $\left(\mathrm{k}_{\text {corr }}\right)$, surface coverage $(\Theta)$, and the efficiency of protection (\% IE) at various doses of Citrus sinensis extract for carbon steel dissolution after two hours of immersion in $0.5 \mathrm{M} \mathrm{H}_{2} \mathrm{SO}_{4}$ at $25^{\circ} \mathrm{C}$.

\begin{tabular}{l|c|c|c|c} 
Inhibitor & $\mathbf{C o n} .(\mathbf{p p m})$ & $\mathbf{K}_{\mathbf{c o r r},\left(\mathbf{m g ~ c m}^{-\mathbf{2}} \mathbf{m i n}^{-\mathbf{1}}\right)}$ & $\boldsymbol{\Theta}$ & $\mathbf{I E} \%$ \\
\hline Blank & $0.5 \mathrm{M}_{2} \mathbf{S O}_{4}$ & 0.0212 & ---- & ---- \\
\hline \multirow{3}{*}{ Citrus sinensis } & 50 & 0.01579 & 0.65 & $65 \%$ \\
\cline { 2 - 5 } & 100 & 0.006 & 0.696 & $69.6 \%$ \\
\cline { 2 - 5 } & 150 & 0.00473 & 0.777 & $77.7 \%$ \\
\cline { 2 - 5 } & 200 & 0.0043 & 0.793 & $79.3 \%$ \\
\cline { 2 - 5 } & 250 & 0.00384 & 0.819 & $81.9 \%$ \\
\cline { 2 - 5 } & 300 & 0.0036 & 0.836 & $83.6 \%$
\end{tabular}

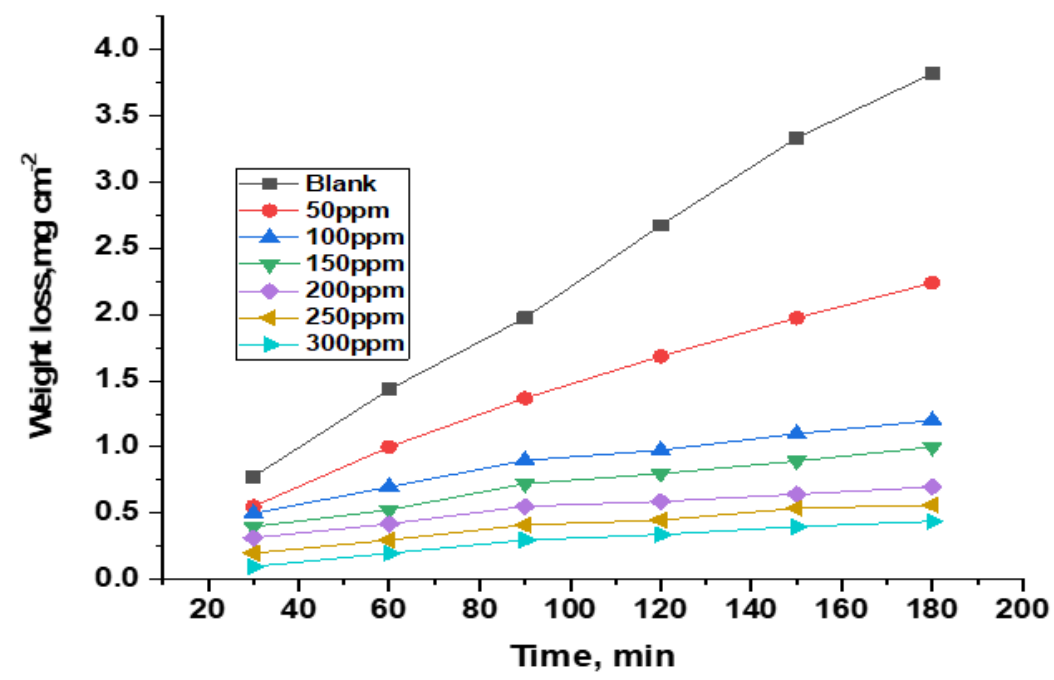

Figure 1. ML- time curves for carbon steel corrosion in $0.5 \mathrm{M} \mathrm{H}_{2} \mathrm{SO}_{4}$ with and without various concentrations of Citrus sinensis extract at $25^{\circ} \mathrm{C}$

\subsection{Effect of temperature.}

Table 4 shows that, by raising the temperature, $\mathrm{k}_{\text {corr }}$ decreased, $(\theta)$ and \%IE increased, indicating that the adsorption process is chemisorption [26].

Table 4. The $\left(\mathrm{k}_{\mathrm{corr}}\right),(\theta)$, and the (\% IE) at various doses of Citrus sinensis for C-steel corrosion after immersion of two hours in half of the molar of sulfuric acid.

\begin{tabular}{|c|c|c|c|c|}
\hline Conc., ppm & Temp., ${ }^{\circ} \mathrm{C}$ & $\begin{array}{c}\mathbf{k}_{\text {corr }}, \\
\text { mg cm}^{-2} \min ^{-1} \\
\end{array}$ & $\boldsymbol{\theta}$ & $\%$ IE \\
\hline \multirow[t]{5}{*}{50} & 25 & 0.01569 & 0.65 & $65 \%$ \\
\hline & 30 & 0.0222 & 0.677 & $67.7 \%$ \\
\hline & 35 & 0.0459 & 0.734 & $73.4 \%$ \\
\hline & 40 & 0.0481 & 0.735 & $73.5 \%$ \\
\hline & 45 & 0.1446 & 0.794 & $79.4 \%$ \\
\hline \multirow[t]{5}{*}{100} & 25 & 0.006 & 0.696 & $69.6 \%$ \\
\hline & 30 & 0.0082 & 0.747 & $74.7 \%$ \\
\hline & 35 & 0.011 & 0.844 & $84.4 \%$ \\
\hline & 40 & 0.0164 & 0.855 & $85.5 \%$ \\
\hline & 45 & 0.0275 & 0.879 & $87.9 \%$ \\
\hline \multirow[t]{5}{*}{150} & 25 & 0.00473 & 0.777 & $77.7 \%$ \\
\hline & 30 & 0.0044 & 0.872 & $87.2 \%$ \\
\hline & 35 & 0.0067 & 0.905 & $90.5 \%$ \\
\hline & 40 & 0.0072 & 0.937 & $93.7 \%$ \\
\hline & 45 & 0.01016 & 0.944 & $94.4 \%$ \\
\hline \multirow[t]{2}{*}{200} & 25 & 0.0043 & 0.793 & $79.3 \%$ \\
\hline & 30 & 0.0042 & 0.876 & $87.6 \%$ \\
\hline
\end{tabular}




\begin{tabular}{|c|c|c|c|c|}
\hline Conc., ppm & Temp., ${ }^{\circ} \mathrm{C}$ & $\begin{array}{c}\text { Kcorr } \\
\text { mg cm }^{-2} \text { min }^{-1}\end{array}$ & $\boldsymbol{\theta}$ & $\%$ IE \\
\hline & 35 & 0.0054 & 0.924 & $92.4 \%$ \\
\hline & 40 & 0.0061 & 0.946 & $94.6 \%$ \\
\hline & 45 & 0.0084 & 0.954 & $95.4 \%$ \\
\hline \multirow[t]{5}{*}{250} & 25 & 0.00384 & 0.819 & $81.9 \%$ \\
\hline & 30 & 0.004 & 0.877 & $87.7 \%$ \\
\hline & 35 & 0.0048 & 0.932 & $93.2 \%$ \\
\hline & 40 & 0.0059 & 0.948 & $94.8 \%$ \\
\hline & 45 & 0.00787 & 0.957 & $95.7 \%$ \\
\hline \multirow[t]{5}{*}{300} & 25 & 0.0036 & 0.836 & $83.6 \%$ \\
\hline & 30 & 0.0037 & 0.889 & $88.9 \%$ \\
\hline & 35 & 0.0047 & 0.933 & $93.3 \%$ \\
\hline & 40 & 0.0056 & 0.951 & $95.1 \%$ \\
\hline & 45 & 0.0072 & 0.961 & $96.1 \%$ \\
\hline
\end{tabular}

3.2.1. Thermodynamic corrosion parameters.

From Arrhenius equation (Fig. 2) Eq. 3, one can calculate $\mathrm{E}_{\mathrm{a}}{ }^{*}$ while from the transition -state equation Eq.4 (Fig. 3), one can determine $\Delta \mathrm{H}^{*}$ and $\Delta \mathrm{S}^{*}$ for carbon steel in half of molar of sulfuric acid with and without the extract at different temperatures.

$$
\log \left(\mathrm{k}_{\text {corr }}\right)=\log \mathrm{A}-\mathrm{E}_{\mathrm{a}}{ }^{*} / 2.303 \mathrm{RT}
$$

A $\log \mathrm{k}_{\text {corr }}$ plot versus $1 / \mathrm{T}$ provided straight lines with slope equivalent- $\Delta \mathrm{E}_{\mathrm{a}}{ }^{*} / 2.303$ RT from which $\left(\Delta \mathrm{E}_{\mathrm{a}}{ }^{*}\right)$ values were determined (Fig. 2) by applying the transition-state equation:

$$
\log \left(\mathrm{k}_{\mathrm{corr}} / \mathrm{T}\right)=\left[\log (\mathrm{R} / \mathrm{Nh})+\left(\left(\Delta \mathrm{S}^{*} / 2.303 \mathrm{R}\right)-\left(\Delta \mathrm{H}^{*} / 2.303 \mathrm{RT}\right)\right]\right.
$$

A $\log$ plot $\left(\mathrm{k}_{\text {corr }} / \mathrm{T}\right)$ versus $1 / \mathrm{T}$ should give a straight line with a slope of $\left(-\mathrm{H}^{* / 2} 2.303 \mathrm{R}\right)$ and an intercept of $\left[\log (\mathrm{R} / \mathrm{Nh})+\left(\Delta \mathrm{S}^{*} / 2.303 \mathrm{R}\right]\right.$ (Fig. 3), respectively, the $\Delta \mathrm{H}^{*}$ and $\Delta \mathrm{S}^{*}$ values were calculated. From the following table, we found that: 1-The lowest values of $\mathrm{Ea}_{\mathrm{a}}{ }^{*}$ and $\Delta \mathrm{H}^{*}$ in the presence of extract than inits absence indicate that chemical adsorption of extract occurs on the carbon steel surface. 2- Negative $\Delta S^{*}$ values indicate that the adsorbed molecules (products) on carbon steel surface are ordered than in the solution (reactants).

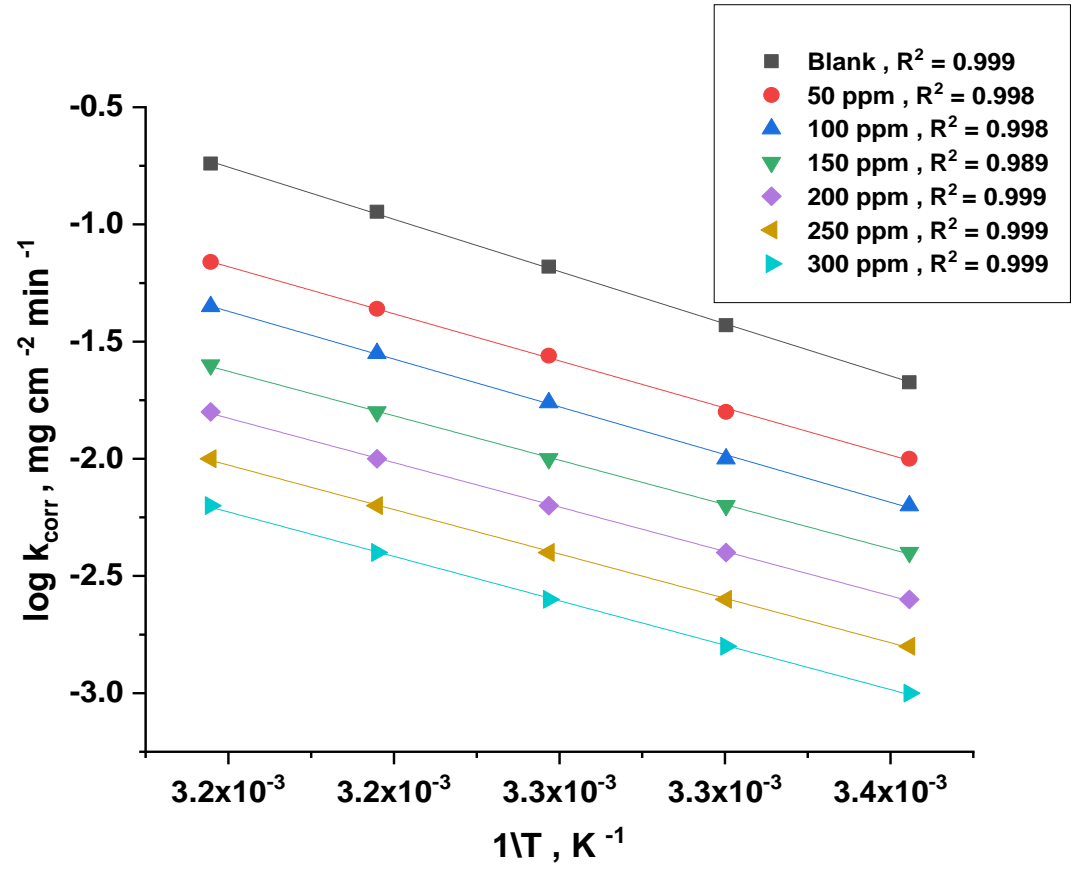

Figure 2. Arrhenius plots for corrosion of carbon steel ( $\mathrm{k}_{\text {corr }}$ ) after two hours immersion in $0.5 \mathrm{M} \mathrm{H}_{2} \mathrm{SO}_{4}$ with and without various doses of Citrus sinensis 


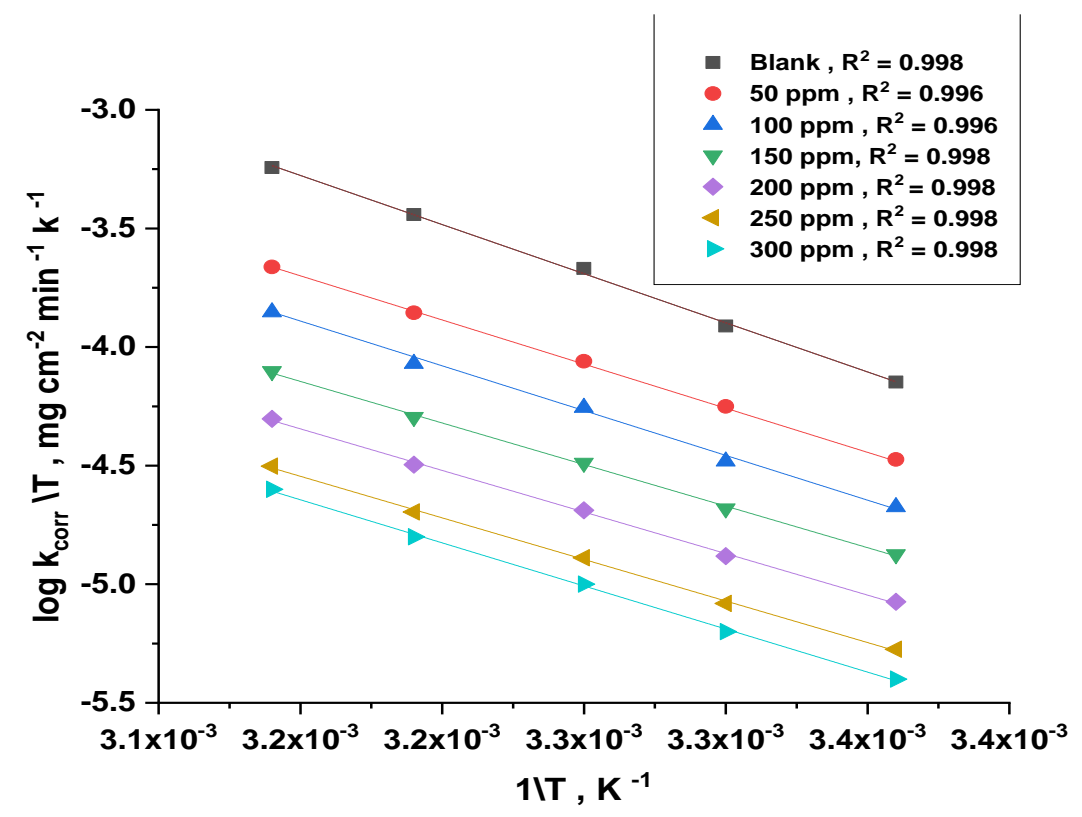

Figure 3. Transition-state $\log$ plots $\left(\mathrm{k}_{\text {corr }} / \mathrm{T}\right)$ vs. 1 / $\mathrm{T}$ for carbon steel in $0.5 \mathrm{M} \mathrm{H}_{2} \mathrm{SO}_{4}$, with and without various doses of Citrus sinensis extract.

Table 5. Activation parameters for corrosion with carbon steel in the absence and existence of various extract doses at $0.5 \mathrm{M} \mathrm{H}_{2} \mathrm{SO}_{4}$

\begin{tabular}{|c|c|c|c|c|}
\hline Compound & $\begin{array}{l}\text { [inh] } \\
\text { ppm }\end{array}$ & $\begin{array}{c}\mathbf{E}_{\mathrm{a}}{ }^{*} \\
\mathrm{~kJ} \mathrm{~mol}^{-1}\end{array}$ & $\begin{array}{c}{ }^{*} \Delta \mathbf{H} \\
\mathrm{kJ} \mathrm{mol}^{-1}\end{array}$ & $\begin{array}{c}-\Delta S^{*} \\
\mathrm{~J} \mathrm{~mol}^{-1} \mathbf{K}^{-1}\end{array}$ \\
\hline Blank & 0 & 86.6 & 80.5 & 6.8 \\
\hline \multirow{6}{*}{ Citrus Sinensis } & 50 & 81.6 & 75.4 & 26.8 \\
\hline & 100 & 43.3 & 40.7 & 159.3 \\
\hline & 150 & 31.9 & 29.3 & 195.9 \\
\hline & 200 & 30.2 & 27.7 & 202.4 \\
\hline & 250 & 32.6 & 30.1 & 195.9 \\
\hline & 300 & 26.7 & 24.2 & 213.9 \\
\hline
\end{tabular}

\subsection{Adsorption isotherms}

It is found that: This plant extract obeys Temkin adsorption isotherm. Temkin adsorption isotherm is given by the following equation [27]:

$$
\Theta_{\text {coverage }}=(2.303 \mathrm{a})\left[\log \mathrm{K}_{\mathrm{ads}}+\log \mathrm{C}\right]
$$

Where $\Theta$ : is the surface coverage. $\mathrm{K}_{\mathrm{ads}}$ : is the adsorption equilibrium constant a: Heterogeneous factor of CS.

A plot of $\Theta$ versus $\log \mathrm{C}$ (Fig. 4) should give straight lines with slope equals (2.303\a), and the intercept is (2.303 $\backslash$ a) $\log \mathrm{K}_{\text {ads. }}$ The $\Delta \mathrm{G}^{\circ}$ ads can be measured by this equation :

$$
\mathrm{K}_{\text {ads }}=(1155.5) \exp \left(-\Delta \mathrm{G}_{\text {ads }}^{\circ} \backslash \mathrm{RT}\right)
$$

Where 55.5: The dose of water at the interface in $\mathrm{M}$.

The adsorption heat $\left(\Delta \mathrm{H}^{\circ}\right.$ ads $)$ can be calculated according to Van't Hoff's formula, as shown in Fig. 5.

$$
\log \mathrm{K}_{\mathrm{ads}}=\left(-\Delta \mathrm{H}^{\circ} \text { ads } / 2.303 \mathrm{RT}\right)+\text { constant }
$$

By plotting $\log \mathrm{K}_{\text {ads }}$ against $1 / \mathrm{T}$ as shown in Fig. 5, the straight line was obtained with a slope equal to $\left(-\Delta \mathrm{H}^{\circ}\right.$ ads $\left./ \mathrm{R}\right)$. With the fundamental equation (8) we can calculate $\Delta \mathrm{S}^{\circ}$ ads at various temperatures.

$$
\Delta \mathrm{G}_{\text {ads }}^{\circ}=\Delta \mathrm{H}^{\circ}{ }_{\text {ads }}-\mathrm{T} \Delta \mathrm{S}^{\circ}{ }_{\text {ads }}
$$




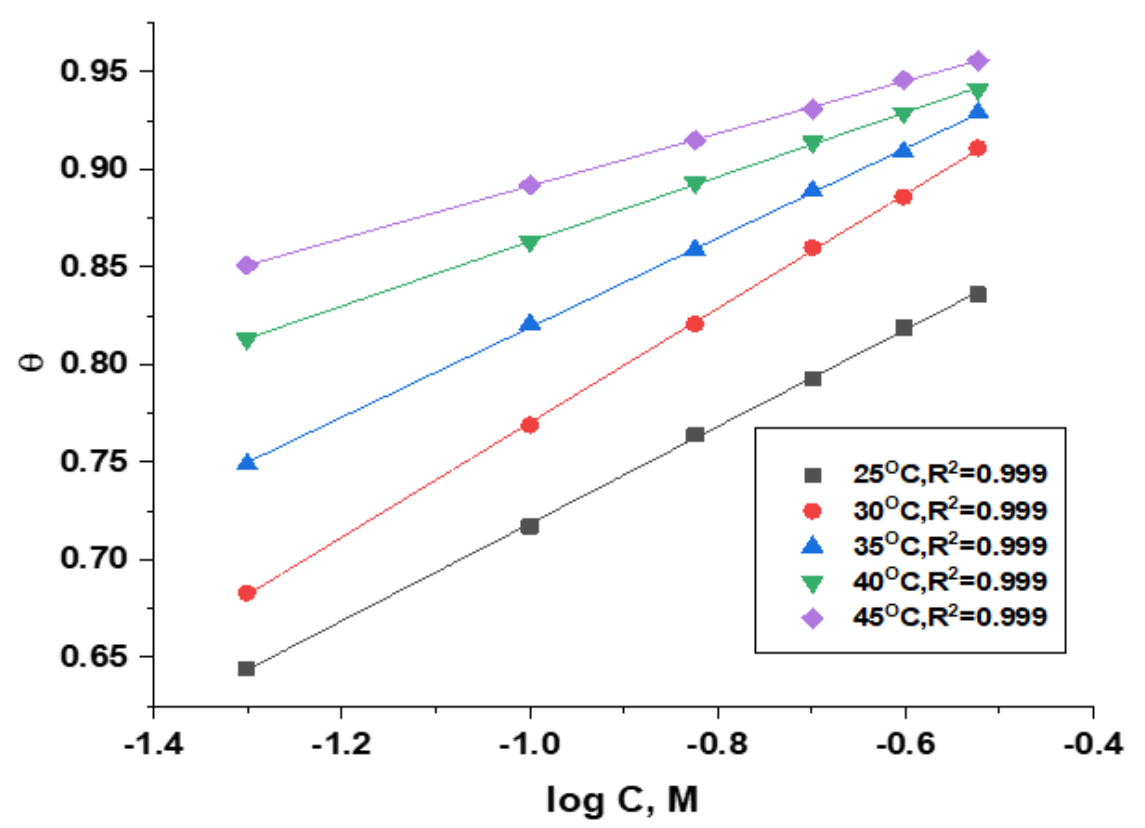

Figure 4. Temkin Adsorption isotherm curves to adsorb Citrus sinensis extract on carbon steel at different temperatures in $0.5 \mathrm{M} \mathrm{H}_{2} \mathrm{SO}_{4}$

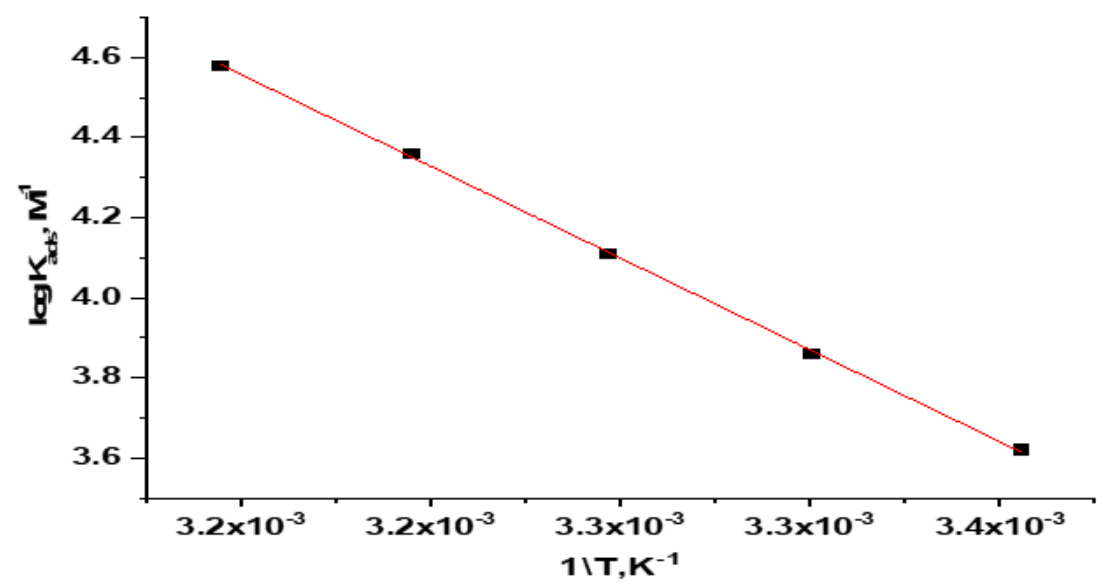

Figure 5. Plots of $\log \mathrm{K}_{\mathrm{ads}}$ vs. 1/ $\mathrm{T}$ (Vant Hoff Eq.) for corrosion of carbon steel in $0.5 \mathrm{M} \mathrm{H}_{2} \mathrm{SO}_{4}$ in the absence and presence of different doses of Citrus sinensis extract

Table 6. Thermodynamic parameters of adsorption of Citrus sinensis extract at various temperatures on the carbon steel surface in $0.5 \mathrm{M} \mathrm{H}_{2} \mathrm{SO}_{4}$

\begin{tabular}{|c|c|c|c|c|}
\hline \multirow[b]{2}{*}{ Inhibitor } & \multicolumn{3}{|c|}{ ( } & \multirow[b]{2}{*}{$\begin{array}{r}-\Delta \mathbf{S}^{\mathbf{0}} \text { ads } \\
\mathbf{J m o l}^{-1} \mathbf{K}^{-1} \\
\end{array}$} \\
\hline & $\begin{array}{c}\text { Temperature } \\
\text { K } \\
\end{array}$ & $\begin{array}{l}-\Delta \mathbf{G}^{\circ} \text { ads } \\
\mathbf{k J} \text { mol }^{-1} \\
\end{array}$ & $\begin{array}{l}-\Delta \mathbf{H}^{\circ} \text { ads } \\
\mathbf{k J} \mathbf{~ m o l}^{-1} \\
\end{array}$ & \\
\hline \multirow{5}{*}{ Citrus sinensis } & 298 & 31.2 & \multirow{5}{*}{88.92} & 396.4 \\
\hline & 303 & 31.9 & & 405.4 \\
\hline & 308 & 34.2 & & 393.4 \\
\hline & 313 & 34.8 & & 401.7 \\
\hline & 318 & 40.7 & & 407.6 \\
\hline
\end{tabular}

From this Table 6 , It is found that: The negative values of $\Delta \mathrm{G}^{\circ}$ ads indicate that the adsorption process is spontaneous.

The negative values of $\left(\Delta \mathrm{H}^{\circ}\right.$ ads $)$ indicate that the adsorption process is exothermic. i.e., the adsorption may be chemical or physical. The value of $\Delta \mathrm{H}^{\circ}$ ads is close to $100 \mathrm{~kJ} \mathrm{~mol}^{-1}$, so it is a chemical reaction. 


\subsection{Electrochemical methods.}

\subsubsection{EIS method.}

The advantages of this method are: It doesn't involve a potential scan. It can be applied to low conductivity media. Fig. 6 represents the equivalent circuit used to fit EIS data. In this method, the results have been depicted graphically by Nyquist plots Figs. (7 \&8). As reported before [28], a semicircular impedance spectra in a higher frequency region were depicted in response to the charge transfer, frequency dispersion, mass transfer, and occurrence of a thin protective layer on meta's surface. The charge transfer resistance $\left(\mathrm{R}_{\mathrm{ct}}\right)$ was used to calculate $\%$ IE. The double-layer capacity $\left(\mathrm{C}_{\mathrm{dl}}\right)$ is defined as:

$$
\mathrm{C}_{\mathrm{dl}}=\mathrm{Y}_{\mathrm{o}}\left(\omega_{\max }\right)^{\mathrm{n}-1}
$$

Where $Y_{o}$ is the CPE constant and $\omega=2 \pi f_{\max }$ is the angular frequency $(\mathrm{rad} / \mathrm{s}), \mathrm{f}$ is maximum frequency, and $\mathrm{n}$ is the parameter deviation for the CPE: $-1 \leq \mathrm{n} \leq 1$

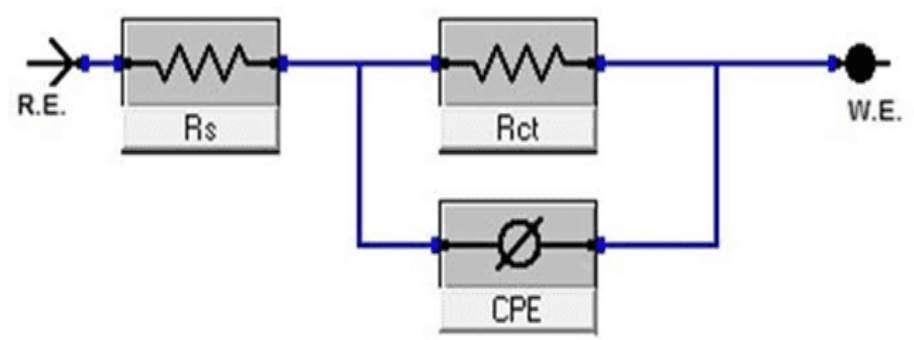

Figure 6. Circuit model used to match experimental EIS

The \%IE was calculated as below:

$$
\% \mathrm{IE}=\left[1-\mathrm{R}_{\mathrm{ct} \text { (inh0 } 0} / \mathrm{R}_{\mathrm{ct}}(\mathrm{free})\right] \times 100
$$

The quantitative results obtained from this st6udy are recorded in Table 7. A noticeable increase in \%IE is seen in increasing the dose of extract. As reported before [29], by increasing doses of extract, the $\mathrm{R}_{\mathrm{ct}}$ values increase, and $\mathrm{C}_{\mathrm{dl}}$ values decrease, which may be ascribed toward the extract's adsorption on the carbon steel surface.

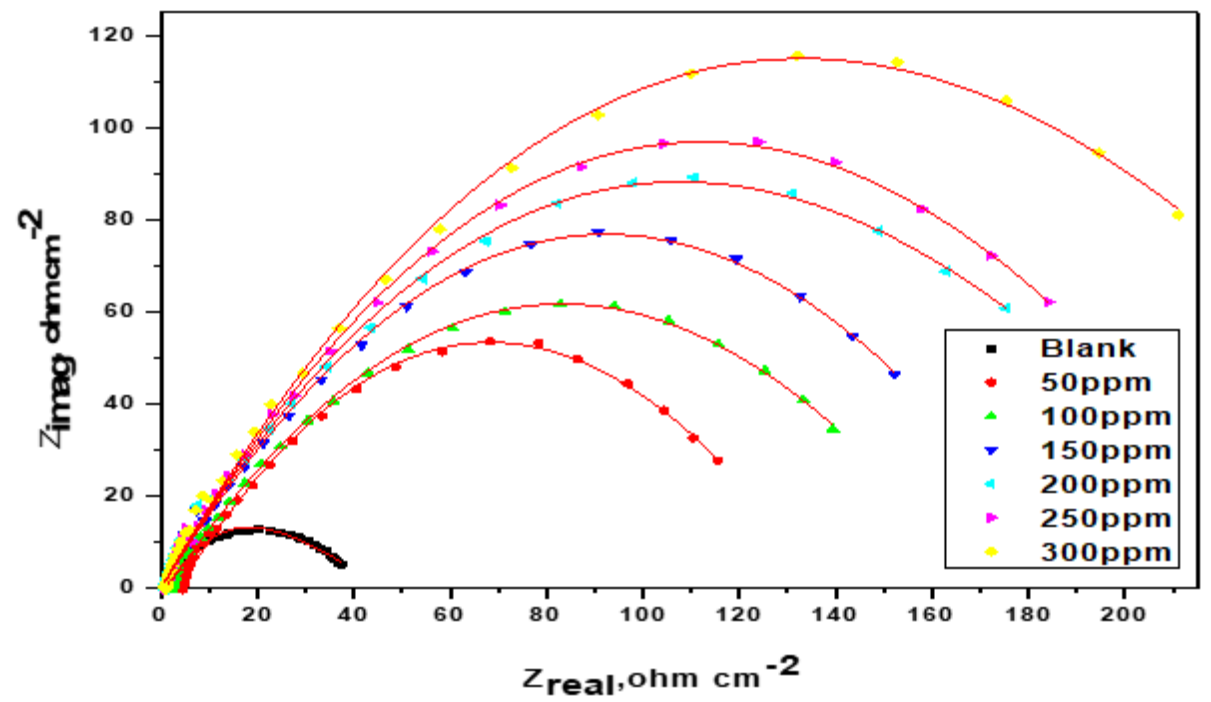

Figure 7. Nyquist plots for carbon steel corrosion in half of the molar of sulfuric acid without and with various Citrus sinensis doses at $25^{\circ} \mathrm{C}$ 


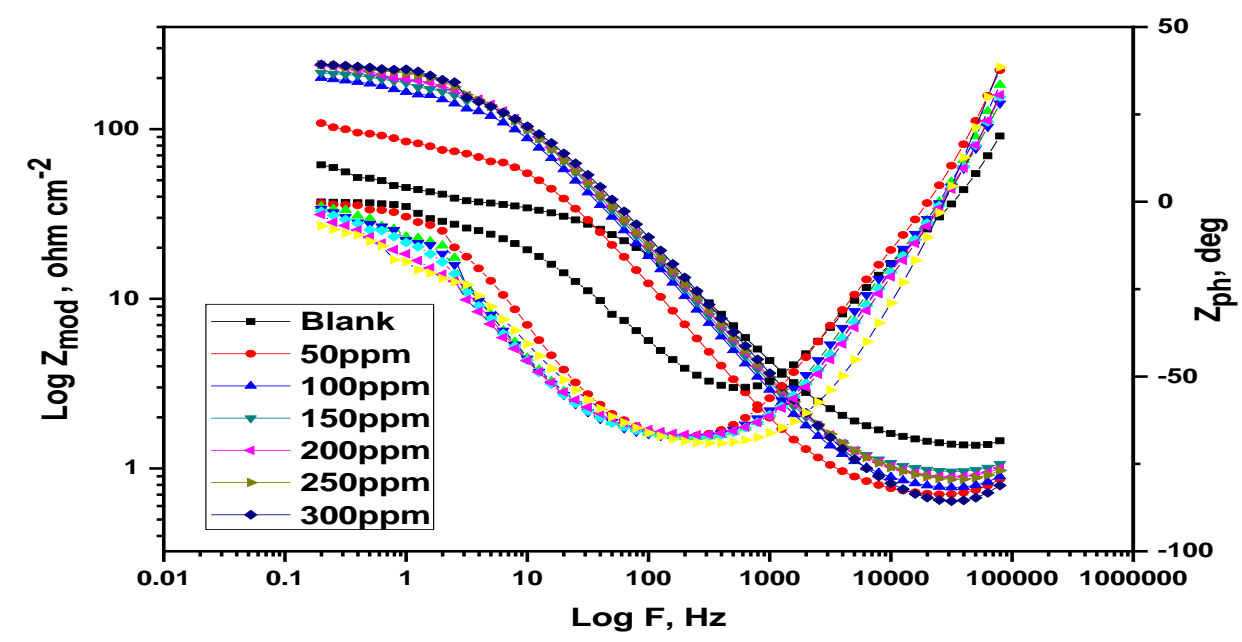

Figure 8. Bode plots for carbon steel corrosion in half of the molar of sulfuric acid with and without various Citrus sinensis doses at $25^{\circ} \mathrm{C}$.

Table 7. EIS for carbon steel corrosion in half of the molar of sulfuric acid with and without various Citrus

\begin{tabular}{l|c|c|c|c}
\multirow{2}{*}{ Conc., ppm } & \multicolumn{2}{|c}{ sinensis doses at $25^{\circ} \mathbf{C}$} \\
& $\begin{array}{c}\mathbf{R}_{\mathbf{c t}} \\
\mathbf{\Omega} \mathbf{~ c m}^{\mathbf{2}}\end{array}$ & $\begin{array}{c}\mathbf{C}_{\mathbf{d l}} \\
\boldsymbol{\mu} \mathbf{F} \mathbf{~ c m}^{-\mathbf{2}}\end{array}$ & $\boldsymbol{\theta}$ & \multirow{2}{*}{$\mathbf{I E}$} \\
\hline Blank & 26 & 214 & -- & -- \\
\hline 50 & 90.66 & 168 & 0.713 & 71.3 \\
\hline 100 & 93.50 & 145 & 0.722 & 72.2 \\
\hline 150 & 93.76 & 132 & 0.723 & 72.3 \\
\hline 200 & 100.5 & 111 & 0.741 & 74.1 \\
\hline 250 & 125.4 & 91.9 & 0.793 & 79.3 \\
\hline 300 & 131.4 & 89.9 & 0.802 & 80.2
\end{tabular}

\subsubsection{PP technique.}

This method determines the rate of metal corrosion quickly. When carbon steel is dipped in the acid solution, which is considered a corrosive medium, oxidation and reduction processes occur on its surface. Tafel is used to describing the mechanism of dissolution of carbon steel in the absence and the existence of the extract [30].

From the following table, we found that:

1-From the small changes in the values of Ecorr (less than $\pm 85 \mathrm{mV}$ ), It shows that the extract is of mixed type [31] (affect on anodic and cathodic reactions) of carbon steel in half of the molar of sulfuric acid as in Table 8 .

2-The protection efficiency rises with rising the dose of the plant extract, but the density of the corrosion current ( $\left.i_{\text {corr }}\right)$ decreases, as in Table 8. This indicates that the extract reduces the dissolution of carbon steel in half of the sulfuric acid.

3- Values of $\beta_{\mathrm{c}}, \beta_{\mathrm{a}}$ change slightly with rising the dose of the plant extract, meaning that the extract affects the dissolution of the metal and also the hydrogen evolution (i.e., mixed type inhibitor), and the parallel Tafel lines (Fig. 9) indicates that there is no change in the mechanism of the process in presence and absence of the extract [32].

Table 8. Impact of doses of Citrus sinensis on $\left(\mathrm{E}_{\text {corr }}\right),\left(\mathrm{i}_{\text {corr }}\right),\left(\beta_{\mathrm{c}}, \beta_{\mathrm{a}}\right),\left(\mathrm{k}_{\mathrm{corr}}\right),(\theta)$ and $(\% \mathrm{IE})$ in $0.5 \mathrm{M} \mathrm{H}_{2} \mathrm{SO}_{4}$.

\begin{tabular}{|c|c|c|c|c|c|c|c|}
\hline $\begin{array}{l}\text { Conc. } \\
\text { Ppm }\end{array}$ & $\begin{array}{c}\text { icorr } \\
\mu \mathrm{A} \mathrm{cm} \mathbf{c m}^{-2}\end{array}$ & $\begin{array}{c}-E_{\text {corr }} \\
\text { mVvs SCE }\end{array}$ & $\begin{array}{c}\beta c \\
\text { mVdec }^{-1}\end{array}$ & $\begin{array}{c}\beta a \\
\text { mVdec }^{-1} \\
\end{array}$ & $\begin{array}{l}\mathbf{k}_{\text {corr }} \\
\text { mpy }\end{array}$ & $\boldsymbol{\theta}$ & $\% \mathrm{IE}$ \\
\hline 0.0 & 156 & 549 & 228.2 & 71.90 & 345.4 & -- & -- \\
\hline 50 & 149 & 547 & 169.2 & 79.70 & 68.03 & 0.803 & 80.3 \\
\hline
\end{tabular}




\begin{tabular}{|c|c|c|c|c|c|c|c|}
\hline $\begin{array}{l}\text { Conc. } \\
\text { Ppm }\end{array}$ & $\begin{array}{c}\text { icorr } \\
\mu \mathrm{A} \mathrm{cm}^{-2}\end{array}$ & $\begin{array}{c}\text {-Ecorr } \\
\text { mVvs SCE }\end{array}$ & $\begin{array}{c}\beta c \\
\mathrm{mVdec}^{-1}\end{array}$ & $\begin{array}{c}\beta a \\
\text { mVdec }^{-1}\end{array}$ & $\begin{array}{l}\text { Kcorr } \\
\text { mpy }\end{array}$ & $\boldsymbol{\theta}$ & $\%$ IE \\
\hline 100 & 146 & 543 & 124.9 & 86.40 & 67.04 & 0.806 & 80.6 \\
\hline 150 & 140 & 541 & 117.4 & 54.60 & 66.92 & 0.815 & 81.5 \\
\hline 200 & 123 & 536 & 172.5 & 87 & 64.01 & 0.837 & 83.7 \\
\hline 250 & 102 & 533 & 103.4 & 77.30 & 56.41 & 0.865 & 86.5 \\
\hline 300 & 90 & 516 & 157.2 & 87.60 & 46.46 & 0.881 & 88.1 \\
\hline
\end{tabular}

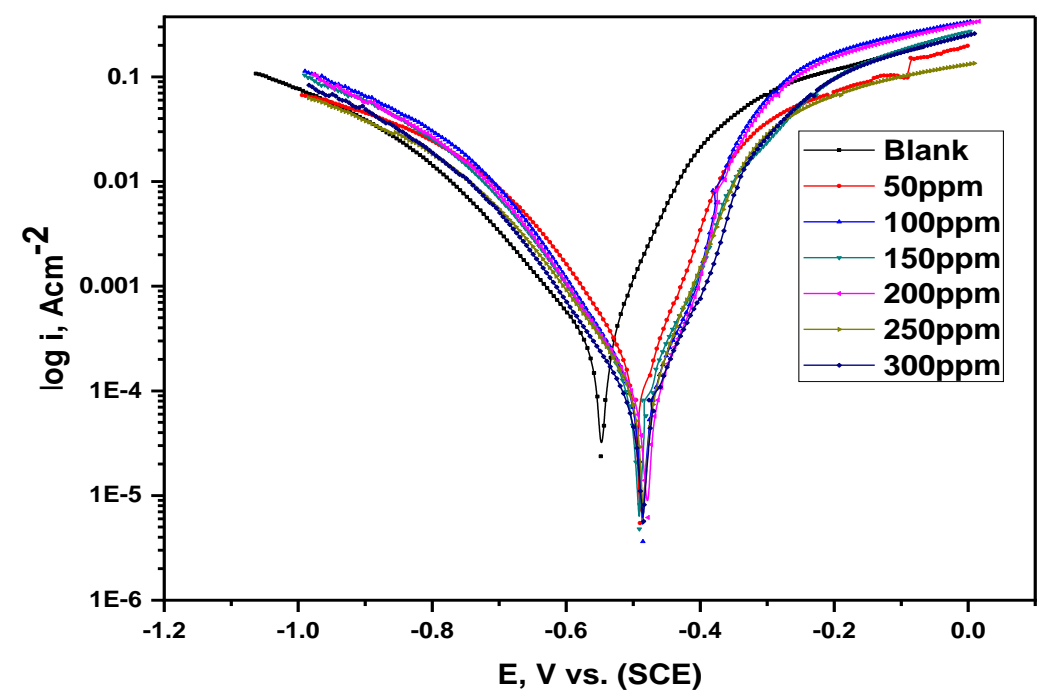

Figure 9. PP curves for the dissolution of carbon steel in half of molar of sulfuric acid with and without various doses of Citrus sinensis extract at $25^{\circ} \mathrm{C}$.

\subsubsection{EFM technique.}

This is a non-destructive method for measuring the corrosion of metals in the corrosion medium, and we can also directly calculate the corrosion current. We do not need to know Tafel constants. The corrosion current density (icorr) reduces with raising the plant extract's dose, so the efficiency of the extract increases, as in Table 9. Measured results are of a high quality due to the causality factors' values near their theoretical values $(2 \& 3)$ as in Table 9. Fig. 10 shows the intermodulation spectra of carbon steel without and with $300 \mathrm{ppm}$ extract at $25^{\circ} \mathrm{C}$.

Table 9. Electrochemical kinetic parameters obtained from EFM technique for carbon steel corrosion in $0.5 \mathrm{M}$ $\mathrm{H}_{2} \mathrm{SO}_{4}$ without and with various Citrus sinensis extract doses at $25^{\circ} \mathrm{C}$

\begin{tabular}{|c|c|c|c|c|c|c|c|c|}
\hline $\begin{array}{l}\text { Conc., } \\
\text { ppm }\end{array}$ & $\begin{array}{c}\mathbf{i}_{\text {corr. }} \\
\mu \mathrm{A} \mathrm{cm}^{-2}\end{array}$ & $\begin{array}{c}\beta_{\mathrm{a}}, \\
\mathrm{mV} \text { dec }^{-1}\end{array}$ & $\begin{array}{c}\beta_{c}, \\
\mathrm{mV} \mathrm{dec}^{-1}\end{array}$ & $\begin{array}{l}\mathbf{k}_{\text {corr }} \\
\mathbf{m p y}\end{array}$ & CF-2 & CF-3 & $\Theta$ & $\%$ IE \\
\hline Blank & 520 & 77.2 & 110.4 & 122.7 & 1.854 & 2.630 & & \\
\hline 50 & 240.2 & 70.4 & 159.5 & 103.8 & 1.869 & 2.664 & 0.538 & 53.8 \\
\hline 100 & 214.1 & 104.4 & 119.6 & 97.81 & 2.223 & 2.232 & 0.588 & 58.8 \\
\hline 150 & 186 & 76.4 & 114.2 & 85 & 1.801 & 3.093 & 0.642 & 64.2 \\
\hline 200 & 159.1 & 89.4 & 110.7 & 72.69 & 1.568 & 3.124 & 0.694 & 69.4 \\
\hline 250 & 135.4 & 88.2 & 99.37 & 67.91 & 1.686 & 3.755 & 0.740 & 74.0 \\
\hline 300 & 104.9 & 96.1 & 121.2 & 61.88 & 1.649 & 3.243 & 0.800 & 80.0 \\
\hline
\end{tabular}

\subsection{Surface morphology.}

\subsubsection{AFM technique.}

The AFM images of carbon steel in $0.5 \mathrm{M} \mathrm{H}_{2} \mathrm{SO}_{4}$ and $300 \mathrm{ppm}$ of the extract are presented in Fig. 11 a-c. The average roughness of carbon steel in $0.5 \mathrm{M} \mathrm{H}_{2} \mathrm{SO}_{4}$ (933.76) is more than the average roughness of carbon steel in $0.5 \mathrm{M} \mathrm{H}_{2} \mathrm{SO}_{4}$ and the extract's existence (39.767) as in Table 10. This indicates that the surface of the carbon steel has become smooth 
due to the formation of a protective layer on its surface from the extract, which leads to the reduction of the corrosion of carbon steel.
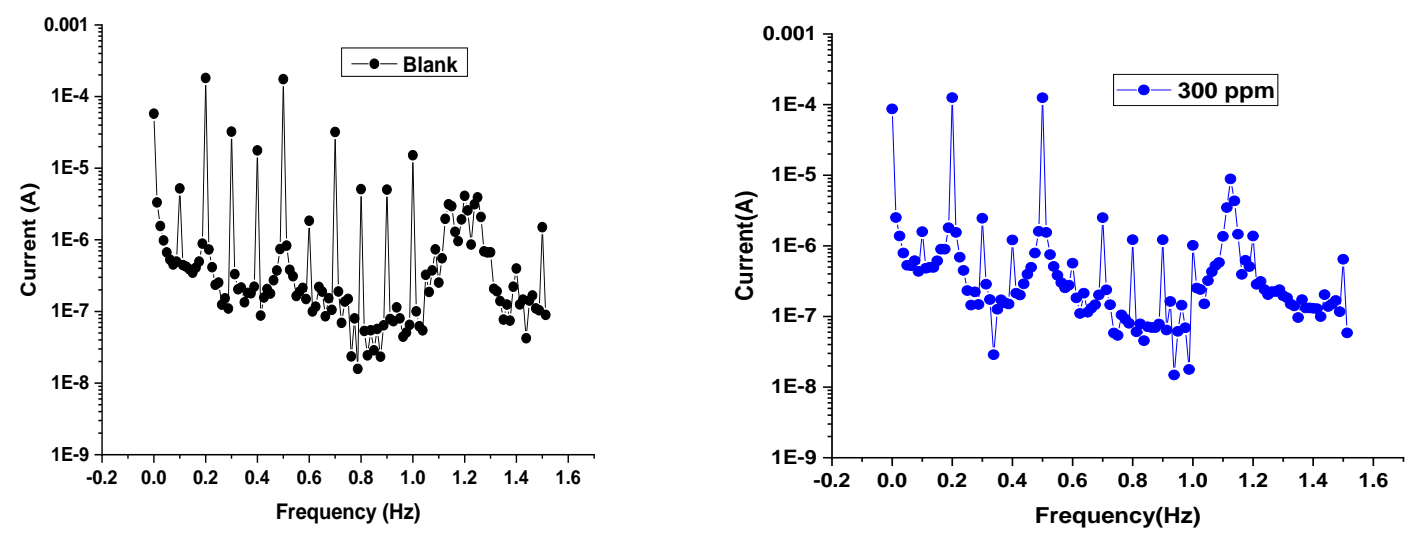

Figure 10. C-steel EFM spectra in $0.5 \mathrm{M} \mathrm{H}_{2} \mathrm{SO}_{4}$ without and with $300 \mathrm{ppm}$ Citrus sinensis extract dose at $25^{\circ} \mathrm{C}$.

Table 10. Roughness data obtained for CS by AFM technique [31, 32].

\begin{tabular}{l|c} 
Sample & Average roughness(Sa) [nm] \\
\hline Polished CS & 17.465 \\
\hline CS immersed in $0.5 \mathrm{M} \mathrm{H}_{2} \mathrm{SO}_{4}$ & 993.76 \\
\hline CS immersed in $\mathbf{0 . 5} \mathbf{M H}_{2} \mathrm{SO}_{4}+\mathbf{3 0 0}$ & 39.767 \\
ppm of Citrus Sinensis &
\end{tabular}

\subsubsection{FTIR technique.}

This technique provides two spectra in the range from 4000 to $400 \mathrm{~cm}^{-1}$. The first spectrometer is the extract alone. While the second one is the carbon steel in the presence of this extract. By comparing the two spectra, we found that there is an interaction between the organic compounds present in the extract and the carbon steel surface forming a layer on the metal surface, and hence, the rate of corrosion decreased.

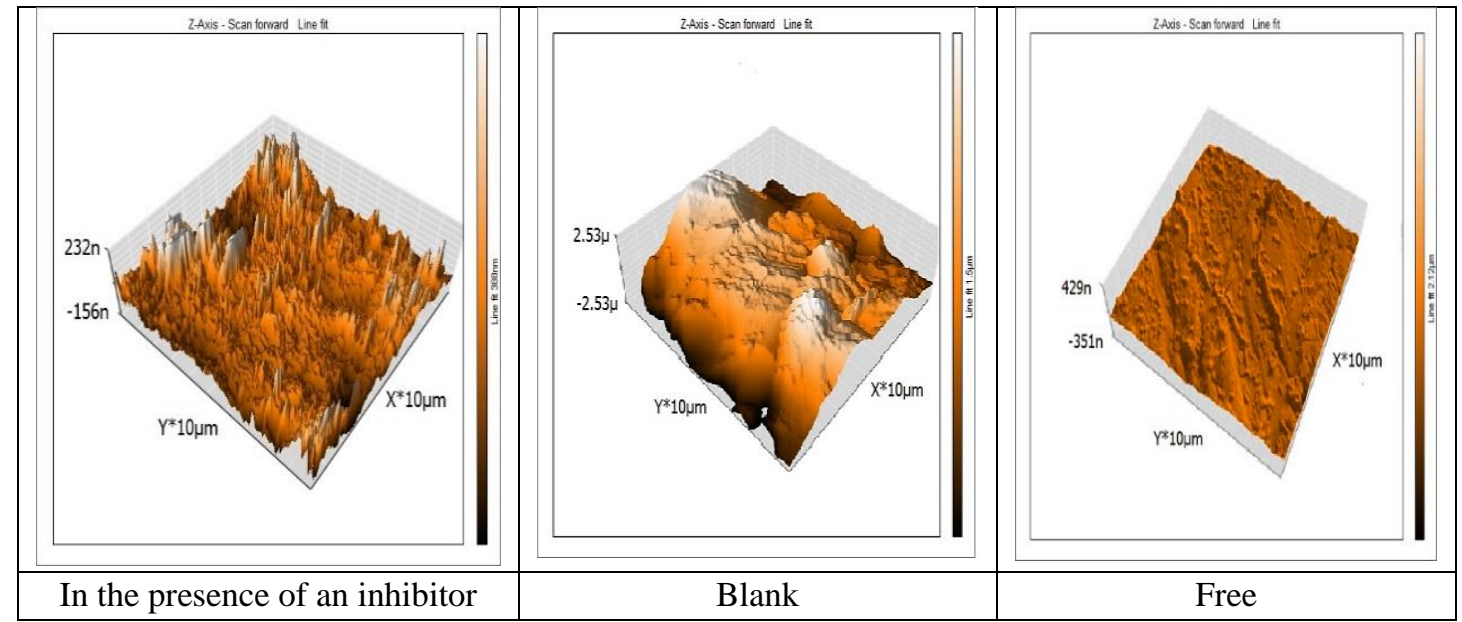

Figure 11. AFM images for carbon steel in (a) inhibited solution of extract (b) blank and (c) free sample.

\subsection{Mechanism of inhibition.}

The mechanism of inhibition action can be explained based on the mode of adsorption. Adsorption is influenced by the chemical structure of extract, its nature and surface charge, the distribution of charge in the molecule [33]. 


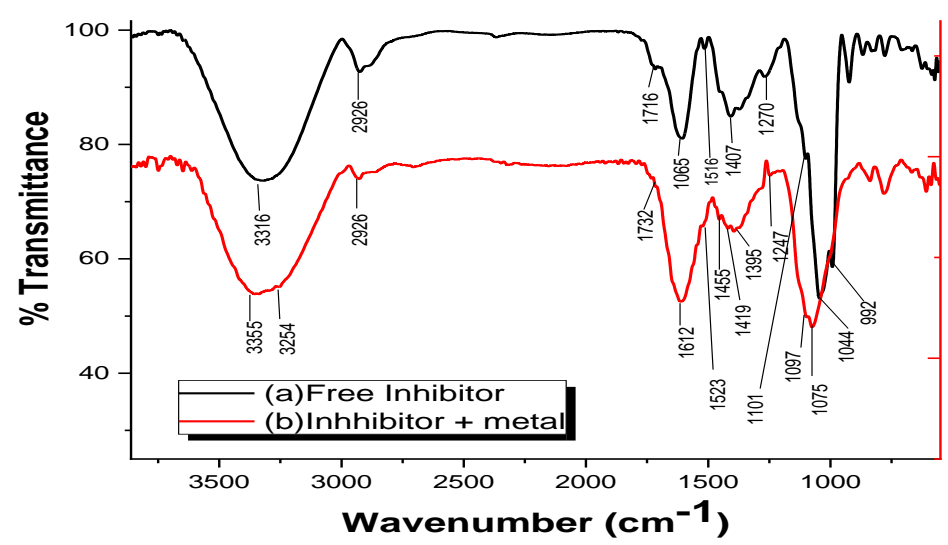

Figure 12. FT - IR spectrum of Citrus sinensis before and after adsorption on the carbon steel surface.

Citrus Sinensis extract has electronegative donor atoms N, O, and $\pi$-electrons of the aromatic ring. These cause the extract's efficient adsorption on carbon steel surface by sharing lone pair of electrons from these donating atoms to d-orbitals of iron, forming chemical adsorption. Also, the protonated extract molecules tend to adsorb onto the metal surface via electrostatic interaction between the positively charged molecules and the negatively charged metal surface, thus facilitating physical adsorption of the extract molecules, forming a protective film that displaces water molecules from the metal surface and protects it against dissolution.

\section{Conclusions}

Citrus sinensis extract acts as a good inhibitor for carbon steel corrosion in a $0.5 \mathrm{M}$ $\mathrm{H}_{2} \mathrm{SO}_{4}$ solution. The inhibition efficiency increased, and the corrosion rate decreased by increasing dose and temperature. The inhibition efficiency of all electrochemical and ML tests was in good agreement. PP measurements demonstrated that the Citrus sinensis extract might be a mixed-type inhibitor. EIS measurements showed that the charge transfer resistance increased. The double layer capacitance decreased by increasing Cirtus sinensis extract dose and, hence, increasing in \% IE. These results can be attributed to the increase in the protective film's thickness formed on the carbon steel surface. The adsorption of Citrus sinensis extracts on the carbon steel surface obeyed Temkin adsorption isotherm. The related kinetic and thermodynamic parameters values obtained suggested that both physisorption and chemisorption mechanisms at low temperature while at higher temperature chemisorption mechanism is preferred. The negative sign of $\Delta \mathrm{G}^{\circ}$ ads values indicated that the adsorption of Citrus sinensis extracts molecules on the carbon steel surface spontaneously.

\section{Funding}

This research received no external funding.

\section{Acknowledgments}

All our gratitude to the anonymous referees for their careful reading of the manuscript and valuable comments helped shape this paper to the present form. 


\section{Conflicts of Interest}

The authors declare that there is no conflict of interest.

\section{References}

1. Liu, T.; Weyers, R. W. Modeling the dynamic corrosion process in chloride contaminated concrete structures. Cement and Concrete research 1998, 28, 365-379, https://doi.org/10.1016/S00088846(98)00259-2.

2. Zhang, R.; Castel, A.; François, R. Concrete cover cracking with reinforcement corrosion of RC beam during chloride-induced corrosion process. Cement and Concrete Research 2010, 40, 415-425, https://doi.org/10.1016/j.cemconres.2009.09.026.

3. Wang, Y.; Wei, M.; Gao, J.; Hu, J.; Zhang, Y. Corrosion process of pure magnesium in simulated body fluid. Materials letters 2008, 62, 2181-2184, https://doi.org/10.1016/j.matlet.2007.11.045.

4. Benarioua, M.; Mihi, A.; Bouzeghaia, N.; Naoun, M. Mild steel corrosion inhibition by Parsley (Petroselium Sativum) extract in acidic media. Egyptian Journal of Petroleum 2019, 28, 155-159, https://doi.org/10.1016/j.ejpe.2019.01.001.

5. Elabbasy, H.M.; Zidan, S.M.; El-Aziz, A.F.S. Inhibitive behavior of Ambrosia Maritima extract as an ecofriendly corrosion inhibitor for carbon steel in 1M HCI. Zaštita materijala 2019, 60, 129-146, https://doi.org/10.5937/zasmat1902129E.

6. Elabbasy, H.M.; Fouda, A.S. Olive leaf as green corrosion inhibitor for C-steel in Sulfamic acid solution. Green Chemistry Letters and Reviews 2019, 12, 332-342, https://doi.org/10.1080/17518253.2019.1646812.

7. Fouda, A.E.-A.S.; Eissa, M. Adenium obesum Extract as a Safe Corrosion Inhibitor for C-Steel in $\mathrm{NaCl}$ Solutions: Investigation of Biological Effects. Journal of Bio- and Tribo-Corrosion 2020, 6, 1-11, https://doi.org/10.1007/s40735-020-00394-3.

8. Almzarzie, K.; Falah, A.; Massri, A.; Kellawi, H. Electrochemical Impedance Spectroscopy (EIS) and Study of Iron Corrosion Inhibition by Turmeric Roots Extract (TRE) in Hydrochloric Acid Solution. Egyptian Journal of Chemistry 2019, 62, 501-512, https://dx.doi.org/10.21608/ejchem.2018.5295.1476.

9. Addi, B.; Addi, A.; Shaban, A.; Habib, E.; Ait Addi, E.H.; Hamdani, M. Tin corrosion inhibition by molybdate ions in $0.2 \mathrm{M}$ maleic acid solution: Electrochemical and surface analytical study. Mediterranean Journal of Chemistry 2020, 10, 465-476, http://dx.doi.org/10.13171/mjc10502005141394aa.

10. Mukemre, M.; Konczak, I.; Uzun, Y.; Dalar, A. Phytochemical profile and biological activities of Anatolian Plantain (Plantago anatolica). Food Bioscience 2020, 36, https://doi.org/10.1016/j.fbio.2020.100658.

11. Genc, Y.; Dereli, F.T.G.; Saracoglu, I.; Akkol, E.K. The inhibitory effects of isolated constituents from Plantago major subsp. major L. on collagenase, elastase and hyaluronidase enzymes: Potential wound healer. Saudi Pharmaceutical Journal 2020, 28, 101-106, https://doi.org/10.1016/j.jsps.2019.11.011.

12. Fernandes, C.M.; Ferreira Fagundes, T.d.S.; Escarpini dos Santos, N.; Shewry de M. Rocha, T.; Garrett, R.; Borges, R.M.; Muricy, G.; Valverde, A.L.; Ponzio, E.A. Ircinia strobilina crude extract as corrosion inhibitor for mild steel in acid medium. Electrochimica Acta 2019, 312, 137-148, https://doi.org/10.1016/j.electacta.2019.04.148.

13. Saraswat, V.; Yadav, M. Computational and electrochemical analysis on quinoxalines as corrosion inhibitors for mild steel in acidic medium. Journal of Molecular Liquids 2020, 297, https://doi.org/10.1016/j.molliq.2019.111883.

14. Ouakki, M.; Galai, M.; Rbaa, M.; Abousalem, A.S.; Lakhrissi, B.; Touhami, M.E.; Cherkaoui, M. Electrochemical, thermodynamic and theoretical studies of some imidazole derivatives compounds as acid corrosion inhibitors for mild steel. Journal of Molecular Liquids 2020, 319, https://doi.org/10.1016/j.molliq.2020.114063.

15. Al-Nami, S. Corrosion Inhibition Effect and Adsorption Activities of methanolic myrrh extract for $\mathrm{Cu}$ in 2 $\mathrm{M} \mathrm{HNO}_{3}$. International Journal of Electrochemical Science 2020, 15, 1187-1205, https://doi.org/10.20964/2020.02.23.

16. Zhang, S.; Hou, L.; Du, H.; Wei, H.; Liu, B.; Wei, Y. A study on the interaction between chloride ions and $\mathrm{CO}_{2}$ towards carbon steel corrosion. Corrosion Science 2020, 167, https://doi.org/10.1016/j.corsci.2020.108531.

17. El-Aziz, E.S.F.A.; Mahmoud, R.S.; Ibrahim, H.; Ezzat, A.R. Expired nizatidine drug as eco-friendly corrosion Inhibitor for alpha-brass alloy in aqueous solutions. Zaštita materijala 2020, 61, 192-209.

18. Qiang, L.X.; Shijin, C.; Jiahong, H. Papaya leaves extract as a novel eco-friendly corrosion inhibitor for $\mathrm{Cu}$ in $\mathrm{H}_{2} \mathrm{SO}_{4}$ medium. Journal of Colloid and Interface Science 2020, 582, 918-931, https://doi.org/10.1016/j.jcis.2020.08.093.

19. Xiao, L.; Jianxin, P.; Jianren, Z.; Yafei, M.; Cai. C.S. Comparative assessment of mechanical properties of HPS between electrochemical corrosion and spray corrosion. Construction and Building Materials 2020, 237, https://doi.org/10.1016/j.conbuildmat.2019.117735.

20. Aslam, J.; Aslam, R.; Lone, I.H.; Radwan, N.R.; Mobin, M.; Aslam, A.; Alzulaibani, A.A. Inhibitory effect of 2-Nitroacridone on corrosion of low carbon steel in $1 \mathrm{M} \mathrm{HCl}$ solution: An experimental and theoretical 
approach. Journal of Materials Research and Technology 2020, 9, 4061-4075, https://doi.org/10.1016/j.jmrt.2020.02.033.

21. Qiu, J.; Li, Y.; Xu, Y.; Wu, A.; Macdonald, D.D. Effect of temperature on corrosion of carbon steel in simulated concrete pore solution under anoxic conditions. Corros. Sci. 2020, 175, https://doi.org/10.1016/j.corsci.2020.108886.

22. Motawea, M. M.; El-Hossiany, A.; Fouda, A.S. Corrosion Control of Copper in Nitric Acid Solution using Chenopodium Extract. Int. J. Electrochem. Sci. 2019, 14, 1372-1387, https://doi.org/10.20964/2019.02.29.

23. Zhu, H.; Huo, Y.; Wang, W.; He, X.; Fang, S.; Zhang, Y. Quantum chemical calculation of reaction characteristics of hydroxyl at different positions during coal spontaneous combustion. Process Safety and Environmental Protection 2021, 148, 624-635, https://doi.org/10.1016/j.psep.2020.11.041.

24. Fouda, A.S.; Abd El-Maksoud, S.A.; El-Hossiany, A.; Ibrahim, A. Corrosion Protection of Stainless Steel 201 in Acidic Media using Novel Hydrazine Derivatives as Corrosion Inhibitors. Int. J. Electrochem. Sci. 2019, 14, 2187-2207, https://doi.org/10.20964/2019.03.15.

25. Melchers, R.E. Effect of temperature on the marine immersion corrosion of carbon steels. Corrosion, 2002, 58, 768-782, https://doi.org/10.5006/1.3277660.

26. Fouda, A.S.; El-Gharkawy, E.; Ramadan, H.; El-Hossiany, A. Corrosion Resistance of Mild Steel in Hydrochloric Acid Solutions by Clinopodium acinos as a Green Inhibitor, Biointerface Research in A pplied Chemistry 2021, 11, 9786-9803, https://doi.org/10.33263/BRIAC112.97869803.

27. Fouda, A.S.; Abdel Azeem, M.; Mohamed, S.A.; El-Hossiany, A.; El-Desouky, E. Corrosion Inhibition and Adsorption Behavior of Nerium Oleander Extract on Carbon Steel in Hydrochloric Acid Solution. Int. J. Electrochem. Sci. 2019, 14, 3932-3948, https://doi.org/10.20964/2019.04.44.

28. Bashir, S.; Singh, G.; Kumar, A. Shatavari (Asparagus Racemosus) as green corrosion inhibitor of aluminium in acidic medium, $J$ Mater Environ Sci.; 2017, 8, 4284-4291, https://doi.org/10.26872/jmes.2017.8.12.451.

29. Fouda, A.S.; Rashwan, S.; El-Hossiany, A.; El-Morsy, F.E. Corrosion Inhibition of Zinc in Hydrochloric Acid Solution using some organic compounds as Eco-friendly Inhibitors. Journal of Chemical, Biological and Physical Sciences 2019, 9, 001-024, https://doi.org/10.24214/jcbps.A.9.1.00124.

30. Zhu, H.; Huo, Y.; Wang, W.; He, X.; Fang, S.; Zhang, Y. Quantum chemical calculation of reaction characteristics of hydroxyl at different positions during coal spontaneous combustion. Process Safety and Environmental Protection 2021, 148, 624-635, https://doi.org/10.1016/j.psep.2020.11.041.

31. Fouda, A.S.; Eissa, M.; El-Hossiany, A. Ciprofloxacin as Eco-Friendly Corrosion Inhibitor for Carbon Steel in Hydrochloric Acid Solution. Int. J. Electrochem. Sci. 2018, 13, 11096-11112, https://doi.org/10.20964/2018.11.86.

32. Fouda, A.S.; Abd El-Maksoud, S.A.; El-Hossiany, A.; Ibrahim, A. Effectiveness of Some Organic Compounds as Corrosion Inhibitors for Stainless Steel 201 in $1 \mathrm{M} \mathrm{HCl}$ : Experimental and Theoretical Studies. Int. J. Electrochem. Sci. 2018, 13, 9826-9846, https://doi.org/10.20964/2018.10.36.

33. Eid, A.M.; Shaaban, S.; Shalabi, K. Tetrazole-based organoselenium bi-functionalized corrosion inhibitors during oil well acidizing: Experimental, computational studies, and SRB bioassay. Journal of Molecular Liquids 2020, 298, https://doi.org/10.1016/j.molliq.2019.111980. 